\title{
Strain-specific battery of tests for domains of mania: effects of valproate, lithium and imipramine
}

\author{
Shlomit Flaisher-Grinberg ${ }^{1}$ and Haim Einat ${ }^{1,2 *}$ \\ 1 College of Pharmacy, University of Minnesota, Duluth, MN, USA \\ 2 Department of Psychology, Tel-Hai Academic College, Upper Galilee, Israel
}

\section{Edited by:}

John P. Redrobe, H. Lundbeck A/S,

Denmark

\section{Reviewed by:}

Charles H. Large, Glaxosmithkline S.p.A., Italy

Susan Powell, University of California at San Diego, USA

Haim Belmaker, Ben Gurion University

of the Negev, Israel

\section{${ }^{*}$ Correspondence:}

Haim Einat, College of Pharmacy,

University of Minnesota, 123 Life

Science, 1110 Kirby Drive, Duluth, MN

55812, USA.

e-mail: heinat@d.umn.edu
The lack of efficient animal models for bipolar disorder (BPD), especially for the manic pole, is a major factor hindering the research of its pathophysiology and the development of improved drug treatments. The present study was designed to identify an appropriate mouse strain for modeling some behavioral domains of mania and to evaluate the effects of drugs using this strain. The study compared the behavior of four strains: Black Swiss, C57BI/6, CBA/J and A/J mice in a battery of tests that included spontaneous activity; sweet solution preference; light/ dark box; resident-intruder; forced-swim and amphetamine-induced hyperactivity. Based on the 'manic-like' behavior demonstrated by the Black Swiss strain, the study evaluated the effects of the mood stabilizers valproate and lithium and of the antidepressant imipramine in the same tests using this strain. Results indicated that lithium and valproate attenuate the 'manic-like' behavior of Black Swiss mice whereas imipramine had no effects. These findings suggest that Black Swiss mice might be a good choice for modeling several domains of mania and distinguishing the effects of drugs on these specific domains. However, the relevance of the behavioral phenotype of Black Swiss mice to the biology of BPD is unknown at this time and future studies will investigate molecular differences between Black Swiss mice and other strains and asess the interaction between strain and mood stabilizing treatment.

Keywords: behavioral domains, mood stabilizers, strain differences, reward seeking, vigor, aggression

\section{INTRODUCTION}

Bipolar disorder (BPD) is a chronic and debilitating illness which includes alternate episodes of depression and mania (Sadock and Kaplan, 2002). The estimated lifetime prevalence rate of BPD is $3.9 \%$ and the median age of onset is 25 years. It is currently recognized that treatment outcomes for many bipolar patients are relatively poor, as significant side effects, high rates of relapse and lingering residual symptoms are evident (for review, see Miklowitz and Johnson, 2006).

The paucity of appropriate animal models for BPD hinders the research of the pathophysiology and the development of new treatments for this condition (Tecott and Nestler, 2004; Gould and Einat, 2007). A number of possible approaches for the development of new models for BPD and for mania include models based on molecular or genetic manipulations [e.g., Ralph-Williams et al., 2003; Machado-Vieira et al., 2004; Einat and Manji, 2006; Roybal et al., 2007; Malkesman et al., 2009), models based on pharmacological interventions (Antelman et al., 1998; Gould et al., 2007; Riegel et al., 2009)] and models induced by environmental stressors [e.g., sleep deprivation (Gessa et al., 1995), dominant-submissive behavior (Knapp et al., 2002; Malatynska and Knapp, 2005), swim stress (Flaisher-Grinberg and Einat, 2009b)].

An additional possible approach emphasizes the identification or development of model animals (Insel, 2007). A model animal can be a specific species or a strain (either standard or with targeted mutation) which demonstrates behavioral or biological similarities with a disorder and may therefore be more homologous with it (Insel, 2007; Ashkenazy et al., 2008; Flaisher-Grinberg et al., 2008;
Malkesman et al., 2009). This approach was the conceptual basis for the development of strains with direct mutations to be used as models for mania (Ralph-Williams et al., 2003; Roybal et al., 2007). However, the identification of appropriate standard mice strains was also found productive. For example, strain variations in the effects of amphetamine and lithium suggest that only a few strains are suitable for use in the amphetamine-induced hyperactivity model of mania (Gould et al., 2007). Preliminary experiments in our laboratory suggest that based on their behavioral repertoire, mice from the Black Swiss (BS) strain may be more suitable for use in modeling a number of the domains of mania compared with other strains. Specifically, BS mice were found to demonstrate 'manic-like' increased risk-taking and reward-seeking behaviors as well as an elevated response to psychostimulants compared with C57Bl/6 mice (Hiscock et al., 2007; Flaisher-Grinberg and Einat, 2009a).

The present study was designed to continue and explore the utility of the BS strain for modeling domains of mania. In Stage 1 , the behavior of BS mice was assessed in a continuous battery of tests relevant to the manic pole of BPD, including spontaneous activity, sweet solution preference, light/dark box, forced swim test (FST), resident-intruder and amphetamine-induced hyperactivity. These tests are part of a broader battery of tests that was suggested to model separate domains of mania (Einat, 2006). From this proposed battery we chose to utilize the tests that have better validation in the context of affective disorders (for elaborated details, see Flaisher-Grinberg and Einat, 2009a). In Stage 2, in order to test the pharmacological (predictive) validity of the battery, the effects of 
the prototypic mood stabilizers valproate and lithium, and of the tricyclic antidepressant imipramine, on the behavior of BS mice were evaluated. Given that pharmacological validity is supported when drugs that are effective in the disorder (i.e., mood stabilizers such as lithium and valproate) are effective in the model while drugs that are not effective in the disorder (i.e., prototypic antidepressant such as imipramine) are not effective in the model (Willner, 1991) and in accordance with their effects in manic patients (Miklowitz and Johnson, 2006), it was hypothesized that valproate and lithium, but not imipramine, would induce an anti-manic effect.

\section{MATERIALS AND METHODS SUBJECTS}

For Stage 1, Black Swiss (Taconic, NY, USA), C57Bl/6 (Harlan, IN, USA), CBA/J and A/J (Jackson laboratory, ME, USA) mice were used. The selection of these strains was based on previous results in the amphetamine-induced hyperactivity model (Monleon et al., 1995; Agmo et al., 1997; Anjaneyulu et al., 2003; Arban et al., 2005; Gould et al., 2007; Hiscock et al., 2007) and on previous experiments performed in our laboratory. For Stage 2, only BS mice were utilized. All mice were transported to our laboratory, where experimentation started no less than 1 week later to allow for appropriate acclimatization time. Male mice, 10 to 12 weeks old and $25 \pm 7 \mathrm{~g}$ at the start of treatment period, were singly housed in a colony room with constant temperature $\left(22 \pm 1^{\circ} \mathrm{C}\right), 12 / 12$ light dark cycle (lights on/off at 0730/1930) and ad-lib food and water. For the residentintruder test (see Behavioral tests), strain-matched mice served as intruders. Intruders were 7 to 8 weeks old, $22 \pm 5 \mathrm{~g}$ at the start of treatment period and were group housed 3-4 in a cage under the same conditions as described above. All experiments were conducted during the early light phase of the light/dark cycle, in dedicated experimental rooms and under standard fluorescent lights (except for the sweet solution preference test, conducted in the colony room). All experimental procedures followed NIH guidelines and were approved by the University of Minnesota Institutional Animal Care and Use Committee (Protocol No. 0610A94146). The number of animals per group in all experiments was 10-16 except for the amphetamine experiments where group size was half of the original number. Intruder mice were used twice and care was taken to counterbalance first and second exposures across test groups.

\section{DRUGS AND DRUG ADMINISTRATION}

Valproate, lithium and imipramine (SIGMA, St. Lewis, MI, USA) were dissolved in saline to a dose of 50, 100 and $200 \mathrm{mg} / \mathrm{kg}$ (valproate), 100 and $200 \mathrm{mg} / \mathrm{kg}$ (lithium) or 10, 20 and $30 \mathrm{mg} / \mathrm{kg}$ (imipramine) and administered via I.P. injection in a volume of $10 \mathrm{ml} / \mathrm{kg}$. Administration started 1 day before the beginning of the test battery and continued throughout the days of testing. Drugs were administered twice daily, with morning injections $30 \mathrm{~min}$ before testing and evening injections at $8 \mathrm{PM}$. For the amphetamine-induced hyperactivity test, d-amphetamine (SIGMA, St. Lewis, MI, USA) was dissolved in saline to a dose of $1 \mathrm{mg} / \mathrm{kg}$ and administered via I.P. injection in a volume of $10 \mathrm{ml} / \mathrm{kg}$ immediately before the beginning of the test. Vehicle groups received an equivalent volume of saline. Drug doses were chosen based on their effects in animal models of affective disorders (e.g. Monleon et al., 1995; Agmo et al., 1996; Gould et al., 2007) and in studies performed in our laboratory
(Hiscock et al., 2007; Flaisher-Grinberg and Einat, 2009b; FlaisherGrinberg et al., 2009). Schedule of administration was selected based on previous work demonstrating its efficacy in some of the models included in the current study (Hiscock et al., 2007; Flaisher-Grinberg and Einat, 2009b; Flaisher-Grinberg et al., 2009).

\section{EOUIPMENT AND PROCEDURES}

\section{Sequence of experiments}

To minimize the effects of previous tests on later ones in the battery the order of tests was arranged from the less to the more intrusive (McQuade et al., 2003). In Stage 1, one cohort of mice was subjected to two sets of tests separated by 1 week of rest: spontaneous activity test; light/dark box; forced swim test; amphetamine-induced hyperactivity (set 1) and sweet solution preference and resident-intruder tests (set 2). Specific tests were separated by 48 -h rest period. In Stage 2, one cohort of mice was subjected to all six tests conducted on consecutive days in the following sequence: spontaneous activity test; sweet solution preference; light/dark box; resident-intruder test; forced swim test and amphetamine-induced hyperactivity test. The unification of the two test sets to one and the switch from 48 to $24 \mathrm{~h}$ separation between tests followed a number of pilot tests which indicated no difference in the behavioral response of BS mice under these two conditions (data not shown).

\section{Behavioral tests}

Spontaneous activity. Mice were tested for spontaneous activity in $50 \times 25 \times 20 \mathrm{~cm}$ transparent plastic automated activity monitors (Opto3, Columbus Instruments, Columbus, OH, USA). Infrared beam crossings were recorded for $60 \mathrm{~min}$ in 10 -min intervals and total ambulatory activity was calculated across the entire session. At the end of the session mice were returned to their home cages and the boxes were wiped clean with a $10 \%$ alcohol solution.

Sweet solution preference test. Mice were supplied with a bottle of $1 \%$ saccharin solution (SIGMA, St. Lewis, MI, USA) on top of the regular supply of water and food. Saccharin concentration was selected as it is in the high end of the concentration-intake curve (Flaisher-Grinberg et al., 2009) and based on previous work done with BS mice (Hiscock et al., 2007). The saccharin solution bottle was available to the mice throughout the entire sweet solution preference test period. Weights of saccharin solution and water bottles were taken at the beginning of the experiment and every $24 \mathrm{~h}$ thereafter. Sweet solution preference was calculated daily as the ratio of saccharin out of total liquid consumption. For Stage 1, saccharin preference was measured across 4 days and for Stage 2 it was measured across 2 days because it was demonstrated that differences between groups were established within the first 2 days.

Light/dark box. The light/dark box apparatus consisted of a wooden box, $60 \times 40 \times 45 \mathrm{~cm}$, divided by a partition to $1 / 3$ covered, blackpainted segment and $2 / 3$ open, well lit, white-painted segment. Mice were placed in the light compartment with the partition slightly ajar to permit free transitions between compartments. Behavior was digitally recorded from above for a 5-min session and recordings served to manually score the time spent in the light compartment. An entry into the light compartment was scored when all four paws 
of the mouse were in that compartment. At the end of the session mice were returned to their home cages and the area was wiped clean with a $10 \%$ alcohol solution.

Resident-intruder test. Resident mice were transferred in their home cages to an experimental room where cage covers were removed. After a 5-min adaptation period, a younger, previously group-housed mouse (i.e., intruder), was placed into the resident's cage and behavior was digitally recorded from above for a 10-min session. Recordings served to manually score resident's aggressive interactions (defined as attempts to bite, actual bite, boxing postures and wrestling postures) and non-aggressive interactions (defined as other types of body contact including sniffing, allogrooming and body contact). Behaviors performed when not interacting were not scored. The resident's aggression score was calculated as the ratio of aggressive interactions out of total (aggressive + non-aggressive) interactions. At the end of the session the intruder was removed and placed back in its home cage, the resident's cage was covered and both mice were returned to the colony room. To minimize harm to animals, mice were briefly separated when attacks became vicious and included significant biting. Hence, the total time of attacks could not be scored and only numbers of aggressive and non aggressive interactions were scored from recordings. This method was previously shown to be sensitive enough to demonstrate the effects of mood stabilizers in this test (Einat, 2007b).

Forced swim test (FST). Mice were placed for a 6-min session in a vertical cylindrical plastic container $(25 \mathrm{~cm}$ tall $\times 18 \mathrm{~cm}$ diameter $)$, filled to a depth of $15 \pm 1 \mathrm{~cm}$ with tap water at $22 \pm 1^{\circ} \mathrm{C}$. This depth was sufficient to ensure that mice could not escape or touch the floor of the container. At the end of the session, mice were removed from the water, dried with a paper towel, and placed back in their home cage. Water in the container was changed after each session. Sessions were digitally recorded from the side and the last 4 min of each session were scored using an automated acquisition and analysis software (Biobserve, Bonn, Germany). Due to technical problems, sessions from Experiment 3, Stage 2, were manually scored by a trained experimenter, blind to the experimental conditions. Scored behaviors were defined as active (swim and struggle) versus passive (floating with only minimal movements needed to keep head above water) behaviors.

Amphetamine-induced hyperactivity. Mice were administered with amphetamine or vehicle and immediately placed in activity monitors for a 60 -min session, where activity was detected by infrared beams and total ambulatory activity was calculated across the entire session. At the end of the session mice were returned to their home cages and the boxes were wiped clean with a $10 \%$ alcohol solution.

\section{STATISTICAL ANALYSIS}

For Stage 1 of the study, the spontaneous activity, light/dark box, resident-intruder and FST data were analyzed using analyses of variance (ANOVA) with Strain (BS/C57Bl/6/CBA/J/A/J) as a main factor. For the sweet solution preference test, data were analyzed using mixed ANOVA with Strain as a main factor and Day as a repeated measures factor. For the amphetamine-induced hyperactivity test, data were analyzed using a two way ANOVA with Strain and Stimulant (amphetamine/vehicle) as main factors. Significant main or interaction effects were followed by Fisher LSD post hoc comparisons. Significance was assumed at $p<0.05$. For Stage 2 of the study, similar statistics were used except that the main factor in the different ANOVA tests was Drug dose (valproate 0, 50, 100, 200/ lithium $0,100,200$ /imipramine $0,10,20,30$ ) instead of strain.

\section{RESULTS}

\section{STAGE 1: STRAIN DIFFERENCES IN A BATTERY OF MODELS FOR MANIA}

As previously reported (for details see Flaisher-Grinberg et al., 2009), BS mice demonstrated a significantly higher sweet solution preference compared with all other strains and across all 4 days of the test (ANOVA: Strain, $F(3,44)=22.93, p<0.0001$, Day, $F(3,132)=42.63, p<0.0001$, Strain $\times$ Day, $F(9,132)=4.11$, $p<0.001)$. As shown in Table 1 , in comparison with the other strains, BS mice exhibited the highest level of aggression in the resident-intruder test, the lowest immobility time in the FST, the highest amount of time in the light compartment of the light/dark box (except for the CBA/J strain) and the most intense response to amphetamine. In the spontaneous activity test, both BS and C57Bl/6 mice demonstrated similar activity levels which were higher compared with $\mathrm{A} / \mathrm{J}$ and $\mathrm{CBA} / \mathrm{J}$ mice.

\section{STAGE 2: THE EFFECTS OF VALPROATE, LITHIUM AND IMIPRAMINE ON THE BEHAVIOR OF BS MICE TESTED IN A BATTERY OF MODELS FOR MANIA Experiment 1: The effects of valproate in a battery of models for mania} As previously demonstrated (Flaisher-Grinberg and Einat, 2009b), $200 \mathrm{mg} / \mathrm{kg}$ valproate reduced sweet solution preference across the 2 days of the test and $100 \mathrm{mg} / \mathrm{kg}$ valproate reduced sweet solution preference on Day 1 with a similar trend on Day 2 (Figure 1A, Dose, $F(3,36)=9.98, p<0.0001$, Day, $F(1,36)=4.01, p<0.05$, Dose $\times$ Day interaction, $F(3,36)=0.65, p=0.58$, see Figure for results of post hoc comparisons). This effect was found despite the general increase in total liquid consumption following valproate administration (data not shown). As expected (Flaisher-Grinberg et al., 2009), 200 mg/kg valproate increased immobility time in the FST with a similar trend at the $100 \mathrm{mg} / \mathrm{kg}$ dose (Figure 1B, Dose, $F(3,34)=3.16, p<0.05$, see Figure for results of post hoc comparisons). In the amphetamineinduced hyperactivity test, a trend for valproate-induced attenuation of amphetamine-induced hyperactivity was demonstrated, resulting from an attenuation at the $200 \mathrm{mg} / \mathrm{kg}$ dose (Figure 1C, Dose, $F(3,30)=2.66, p=0.06$, Stimulant, $F(1,30)=38.34, p<0.0001$, Dose $\times$ Stimulant interaction, $F(3,30)=2.04, p=0.13$, see Figure for results of post hoc comparisons). Valproate had no effect in the non-amphetamine treated groups.

Valproate had no effect on spontaneous activity across the entire session $(F(3,35)=1.63 p=0.20)$ and across the first 10 -min session $(F(3,35)=0.04 p=0.98)$. Valproate also had no effects on behavior in the light/dark box $(F(3,36)=0.06, p=0.97)$ or the residentintruder test $(F(3,36)=1.84, p=1.57)$. Interestingly, in contrast with the results of Stage 1, mice from the vehicle group demonstrated a very low aggression ratio $($ mean $=0.25, \mathrm{SE}=0.06)$ in the resident-intruder test. $N=10$ /group in each of these three tests.

\section{Experiment 2: The effects of lithium in a battery of models for mania}

As previously demonstrated (Flaisher-Grinberg et al., 2009), $200 \mathrm{mg} / \mathrm{kg}$ lithium reduced sweet solution preference across the 2 days of the test (Figure 2A, Dose, $F(2,44)=8.14, p=0.001$, Day, 
Table 1 | Strain differences in tests for domains of mania.

\begin{tabular}{|c|c|c|c|c|c|}
\hline $\begin{array}{l}\text { Test Measurement } \\
\text { collected }\end{array}$ & Strain & $N$ & Mean score \pm SE & & ANOVA analysis \\
\hline $\begin{array}{l}\text { Resident- intruder test } \\
\text { (Ratio of aggressive/total } \\
\text { interactions) }\end{array}$ & $\begin{array}{l}\text { BS } \\
\text { C57BI/6 } \\
\text { CBA/J } \\
\text { A/J }\end{array}$ & $\begin{array}{l}11 \\
12 \\
12 \\
12\end{array}$ & $\begin{array}{l}0.72 \pm 0.05 \\
0.29 \pm 0.19^{*} \\
0.03 \pm 0.03^{*} \\
0.30 \pm 0.06^{*}\end{array}$ & & $\begin{array}{l}\text { Strain: } F(3,43)=15.37, p<0.0001 .1 \mathrm{BS} \\
\text { mouse was excluded showing unusual } \\
\text { circling behavior }\end{array}$ \\
\hline $\begin{array}{l}\text { Light/Dark box: (Time in } \\
\text { light Compartment - sec) }\end{array}$ & $\begin{array}{l}\text { BS } \\
\text { C57BI/6 } \\
\text { CBA/J } \\
\text { A/J }\end{array}$ & $\begin{array}{l}11 \\
12 \\
12 \\
12\end{array}$ & $\begin{aligned} 152.82 & \pm 5.89 \\
111.25 & \pm 9.82^{*} \\
143.66 & \pm 26.17 \\
87.66 & \pm 22.32^{*}\end{aligned}$ & & $\begin{array}{l}\text { Strain: } F(3,43)=5.17, p<0.01 .1 \mathrm{BS} \text { mouse } \\
\text { was excluded because of camera malfunction }\end{array}$ \\
\hline $\begin{array}{l}\text { Spontaneous activity: } \\
\text { (Total ambulatory activity) }\end{array}$ & $\begin{array}{l}\text { BS } \\
\text { C57BI/6 } \\
\text { CBA/J } \\
\text { A/J }\end{array}$ & $\begin{array}{l}9 \\
10 \\
9 \\
9\end{array}$ & $\begin{array}{l}4347.33 \pm 622.57 \\
4235.90 \pm 400.87 \\
1426.55 \pm 109.64^{*} \\
1486.77 \pm 376.43^{*}\end{array}$ & & $\begin{array}{l}\text { Strain: } F(3,33)=15.27, p<0.0001 \text {. Three } B S \text {, } \\
\text { CBA } / J \text { and } A / J \text { mice and two } C 57 \mathrm{BI} / 6 \text { mice } \\
\text { were excluded because of computer } \\
\text { malfunction }\end{array}$ \\
\hline
\end{tabular}

${ }^{*}$ Represents significant difference from BS mice $(p<0.05) .{ }^{*}$ Represents significant difference between amphetamine- and vehicle-treated group within each strain $(p<0.05)$

$F(1,44)=0.97, p=0.32$, Dose $\times$ Day, $F(2,44)=0.28, p=0.75$, see Figure for results of post hoc comparisons). No lithium effect on total liquid consumption was found in this test (data not shown, Dose, $F(2,44)=0.42, p=0.65$, Day, $F(1,44)=76.77, p<0.0001$, Dose $\times$ Day, $F(2,44)=2.13, p=0.13)$. Lithium had no effect on spontaneous activity across the entire session (Dose, $F(2,45)=0.24$ $p=0.78, N=16 /$ group) and across the first 10-min session (Dose, $F(2,45)=0.08 p=0.92$ ) but it attenuated amphetamineinduced hyperactivity at the $200 \mathrm{mg} / \mathrm{kg}$ dose without affecting the activity of non-amphetamine treated mice (Figure 2C, Dose, $F(2,42)=12.02, p<0.0001$, Stimulant, $F(1,42)=52.20, p<0.00001$, Dose $\times$ Stimulant interaction, $F(2,42)=4.05, p<0.05$, see Figure for results of post hoc comparisons). Lithium had no effects in the FST (Figure 2B, Dose, $F(2,21)=0.06, p=0.93$ ), the light $/$ dark box (Dose, $F(2,45)=0.60, p=0.55, N=16$ /group) or the residentintruder test (Dose, $F(2,43)=1.44, p=0.24, N=16$ /group). Vehicletreated mice demonstrated a relatively low aggression rate in this last test $($ mean $=0.46, \mathrm{SE}=0.06)$.

Experiment 3: The effects of imipramine in a battery of models for mania Imipramine administration did not induce any behavioral changes in the test battery for BS mice (Table 2). No imipramine effect on total liquid consumption in the sweet solution preference test was found (data not shown). As mentioned in the Section "Materials and Methods", due to technical problems the FST results in this experiment were scored manually. Previous pilots conducted in our laboratory demonstrated no differences between manual and automated scores (data not shown). Moreover, the scores of the controltreated group in this experiment are comparable with the scores of the control-treated groups in Experiments 1 (see Figure 1B) and 2 (see Figure 2B) of this stage.

\section{DISCUSSION}

The need to develop more efficient and predictive methods of modeling BPD had been repeatedly emphasized. The present study supports the utility of Black Swiss mice as an appropriate strain to model a number of behavioral domains of the manic pole of BPD. Specifically, the results demonstrate that BS mice show a unique manic-like baseline behavioral pattern and a uniqe response to mood stabilizing drugs compared with other strains. BS mice show a number of 'manic-like' behaviors including increased rewardseeking, risk-taking, aggressive, vigor and goal directed behaviors, as well as intense respone to amphetamine. Moreover, in BS mice, most of these behaviors are ameliorated by the prototypic mood stabilizers valproate and lithium but are not affected by the tryciclic antidepressant imipramine (Table 3), further supporting the relevance of the model to the human syndrom.

Identifying an appropriate model animal, species or strain for the purposes of modeling a specific disorder is an acknowledged and successful method of research. For instance, the Flinders Sensitive 

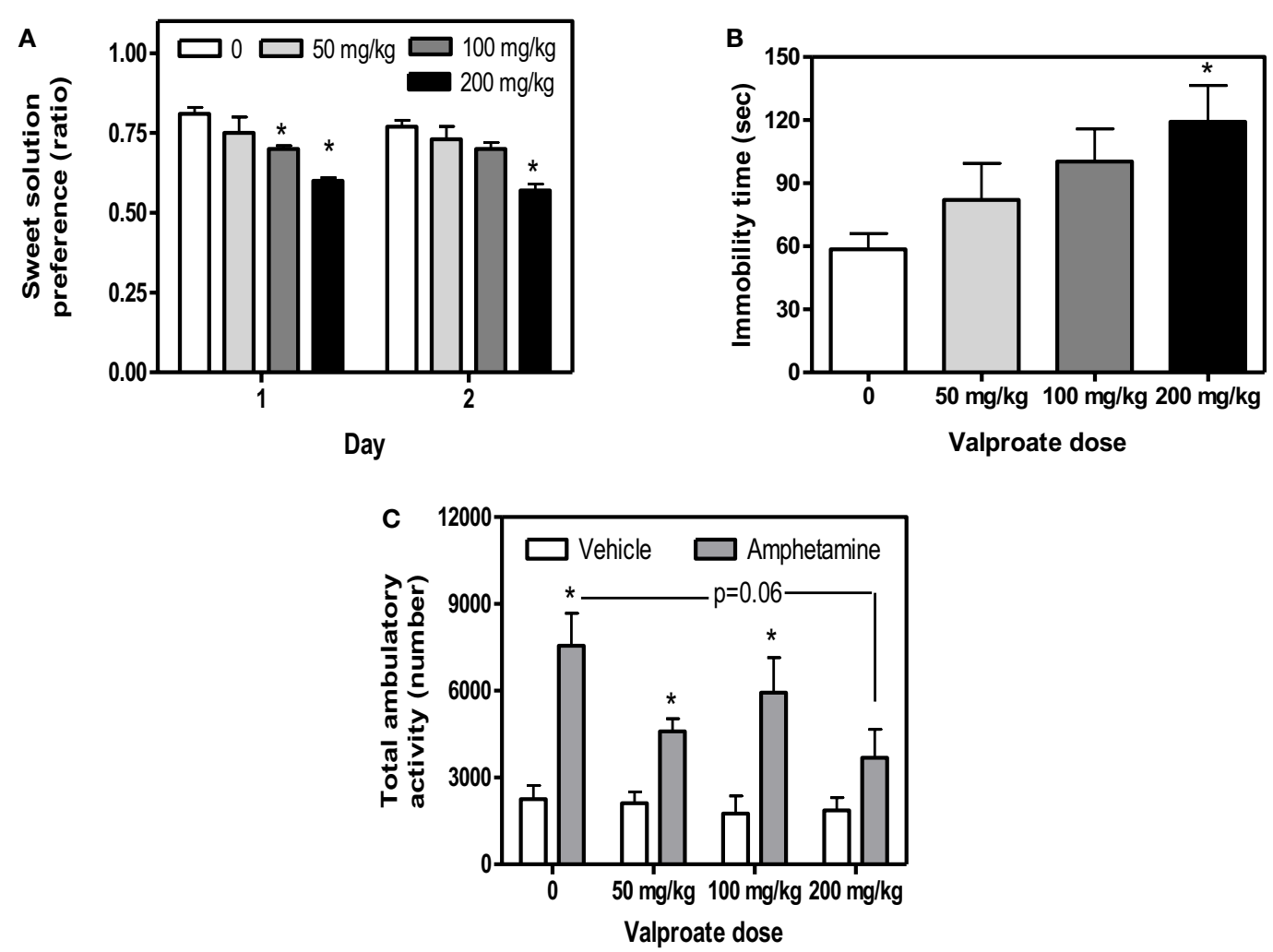

FIGURE 1 | Mean and standard error of (A) saccharin preference ratio on days 1 and 2 of the sweet solution preference test (B) immobility time (s) in the FST of BS mice treated with valproate and (C) total activity of BS mice treated with valproate and amphetamine. *Significantly different from the vehicle group $(p<0.05)$. $N=10$ /group for $(\mathbf{A}, \mathbf{B}), N=5 /$ group for
(C), except for the following: FST; 1 mouse from the $50 \mathrm{mg} / \mathrm{kg}$ and 1 mouse from the $100 \mathrm{mg} / \mathrm{kg}$ group, amphetamine-induced hyperactivity; 1 mouse from the $50 \mathrm{mg} / \mathrm{kg}$ + vehicle group and 1 mouse from the $200 \mathrm{mg} /$ $\mathrm{kg}+$ amphetamine group were excluded from analysis due to automated system malfunctioning. rats line has been used as a model for depression (Overstreet, 1986) and the Alcohol Preferring P rats have been used as a model for alcoholism (Penn et al., 1978). Lewis rats have been used to study the biological mechanisms underlying obsessive compulsive disorder (Brimberg et al., 2007) and Fischer 344 and Lewis rats have been used to study susceptibility to psychoactive drugs and to stress (Suzuki et al., 1988; Cohen et al., 2006). Strain differences have been suggested as a method to define predictive responses to current medications (Porsolt et al., 1978; Gould et al., 2007) and to select appropriate animals for behavioral models of specific disorders and as background for the development of animal with targeted mutations (Crawley, 1999; Gould et al., 2007). In the field of BPD and mania modeling, recent studies identified a number of mice strains with targeted mutations that demonstrate a variety of 'manic-like' behaviors, including mice with targeted mutations of the Clock gene (Roybal et al., 2007), dopamine transporter (Ralph-Williams et al., 2003), and glutamate receptors (Shaltiel et al., 2008) (see Malkesman et al., 2009 for review). The development of model animals through targeted mutations has a number of advantages as they directly indicate possible mechanisms related to the underlying biology of the disorder (Malkesman et al., 2009). However, considering the conceptual and practical problems associated with models based on targeted mutations, there are also advantages in studying the neural basis of strain-specific behaviors (Gould et al.,
2007; Hiscock et al., 2007; Ashkenazy et al., 2008; Flaisher-Grinberg and Einat, 2009b; Flaisher-Grinberg et al., 2009) as well as speciesspecific behaviors of non-treaditional model animals (Smale et al., 2005; Einat, 2007a). Comparison between different strains or different species can provid a strong tool to explore the undelying mechanism of behavior (Smale et al., 2005).

The results of Stage 1 of this study, demonstrating that BS mice show 'manic-like' behaviors compared with other strains, combined with the results of Stage 2 showing that these behaviors are attenuated by mood stabilizers but not by antidepressant treatment, provide face and pharmacological validity to the use of this strain in a specific battery of tests for mania. Moreover, the drug response profile demonstrated by BS mice in the current study is unique as it demonstrate 'anti-manic' effects in tests traditionaly used to asess the effects of depressenogenic manipulation and antidepressant drugs (see discussion below). The differences between the strains and the differences in drug effects can be utilized to (1) select an appropriate strain for modeling purposes (2) explore the relevance of these behavioral phenotypes to the underlying biology of the different strains and (3) screen for new and improved mood stabilizing/anti-manic drugs. It is important to note, however, that the findings demonstrating 'manic-like' behavioral phenotype in BS mice do not imply that these mice are "manic" as there is no evidence at this time that their behavior has identical causative 

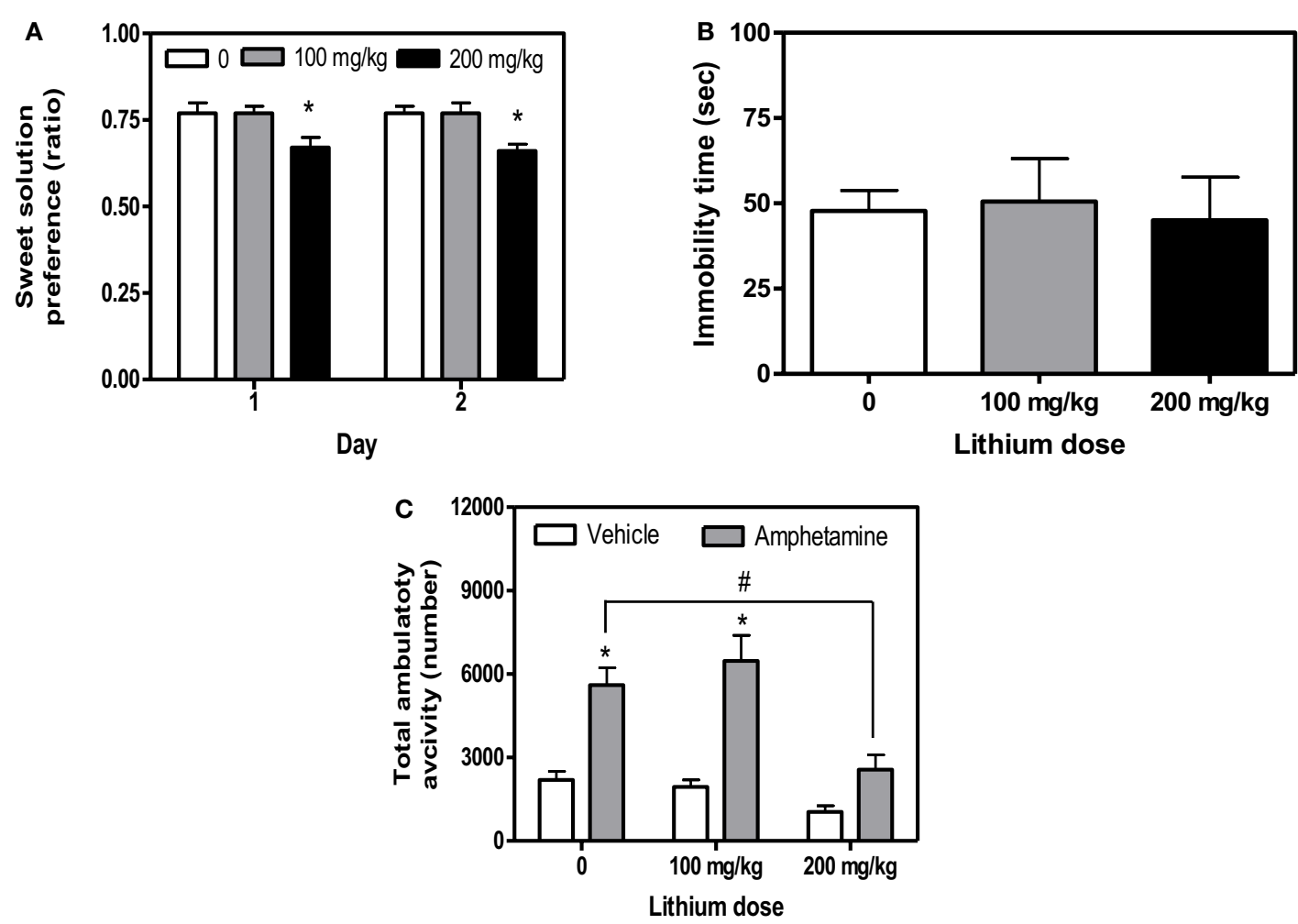

FIGURE 2 | Mean and standard error of (A) saccharin preference on days 1 and 2 of the sweet solution preference test (B) immobility time (s) in the FST of BS mice treated with lithium and (C) total activity of BS mice treated with lithium and amphetamine. ${ }^{*}$ Significantly different from the vehicle group ( $p<0.05$ ); \#difference between amphetamine groups. $N=16$ / group for (A), $N=14 /$ group for (B), $N=8$ /group for (C). In the FST, the results of 2 mice from each group were excluded from the statistical analysis due to a system malfunction during the test. factors or general symptomology with the disorder. Moreover, these findings do not contradict the possibility that other mice strains might also demonstrate 'manic-like' behaviors in these and other relevant tests. Importantly, an investigation of the biochemical and molecular underpinning of the unique set of behaviors demonstrated by BS mice in comparison to other strains is currently performed in our laboratory. A specific emphasis is being placed on molecular pathways which were previously implicated in mania and/or BPD or its treatment [PKC (Einat et al., 2004. 2007), GSK-3 (Gould et al., 2006), BCL-2 (Lien et al., 2008; Chang et al., 2009) and BDNF (Frey et al., 2006a)].

In the current study it was also demonstrated that the profiles of the effects of lithium and valproate were not identical (see Table 3 ). Whereas this may seem to question the relevance of the results to the human syndrome, it is suggested that the varied effects in the model are not different than the variability of effects of mood stabilizers in patients (Cousins and Young, 2007). In fact, the differences between the specific effects of lithium and valproate across the test battery suggests a way to distinguish the effects of treatment on separate domains of the disorder (Einat, 2007a). It is however also possible that some of the differences in effects are related to drug levels in the brain. In the present study, drug doses were chosen based on their effects in animal models of affective disorders. For example, 100 and $200 \mathrm{mg} / \mathrm{kg}$ lithium increased the threshold for rewarding intracranial self stimulation (Mavrikaki et al., 2009), $50 \mathrm{mg} / \mathrm{kg}$ of lithium reduced amphetamine hyperactivity (Borison et al., 1978). Adminsitration of $200 \mathrm{mg} / \mathrm{kg}$ lithium reduced aggression in mice (Nakao et al., 1985) and lithium at $100 \mathrm{mg} / \mathrm{kg}$ and valproate at $200 \mathrm{mg} / \mathrm{kg}$ attenuated neuropeptide S-induced hyperactivity (Castro et al., 2009). Because specific drug levels in plasma or brain were not assessed in the present study the possibility that other doses and dosing regimens might have different effect profiles is left open. However, the similarities between drug doses in this and in previous studies support the relevance of the current findings. Moreover, it is also possible that even when plasma levels are monitored, the information is not enough to make clear extrapolations to the human conditions. First, the metabolism of mice is different than that of humans and therefore the kinetics of drugs is also different. For example, whereas the standard dose of imipramine for the treatment of depression is 1-4 mg/kg per day (e.g. Leucht et al., 2000), doses used in animal experimentation range between 10 and $30 \mathrm{mg} /$ $\mathrm{kg}$ per day (e.g. Einat et al., 1999). Additionally, the presence of the drug in the plasma is not always a representation of its presence in the brain (e.g. Kovacsics and Gould, 2009).

Some of the drug effects in the present study might seem to be in contrast with prior reports. All three drugs were previously found to increase sweet solution preference [lithium (Orsetti et al., 2006) valproate (Monleon et al., 1995; Papp et al., 1996) imipramine (Papp et al., 1996)]. However, these 'antidepressantlike' effects were found in animals which were previously exposed 
Table 2 | Behavioral effects of imipramine administration in tests for domains of mania.

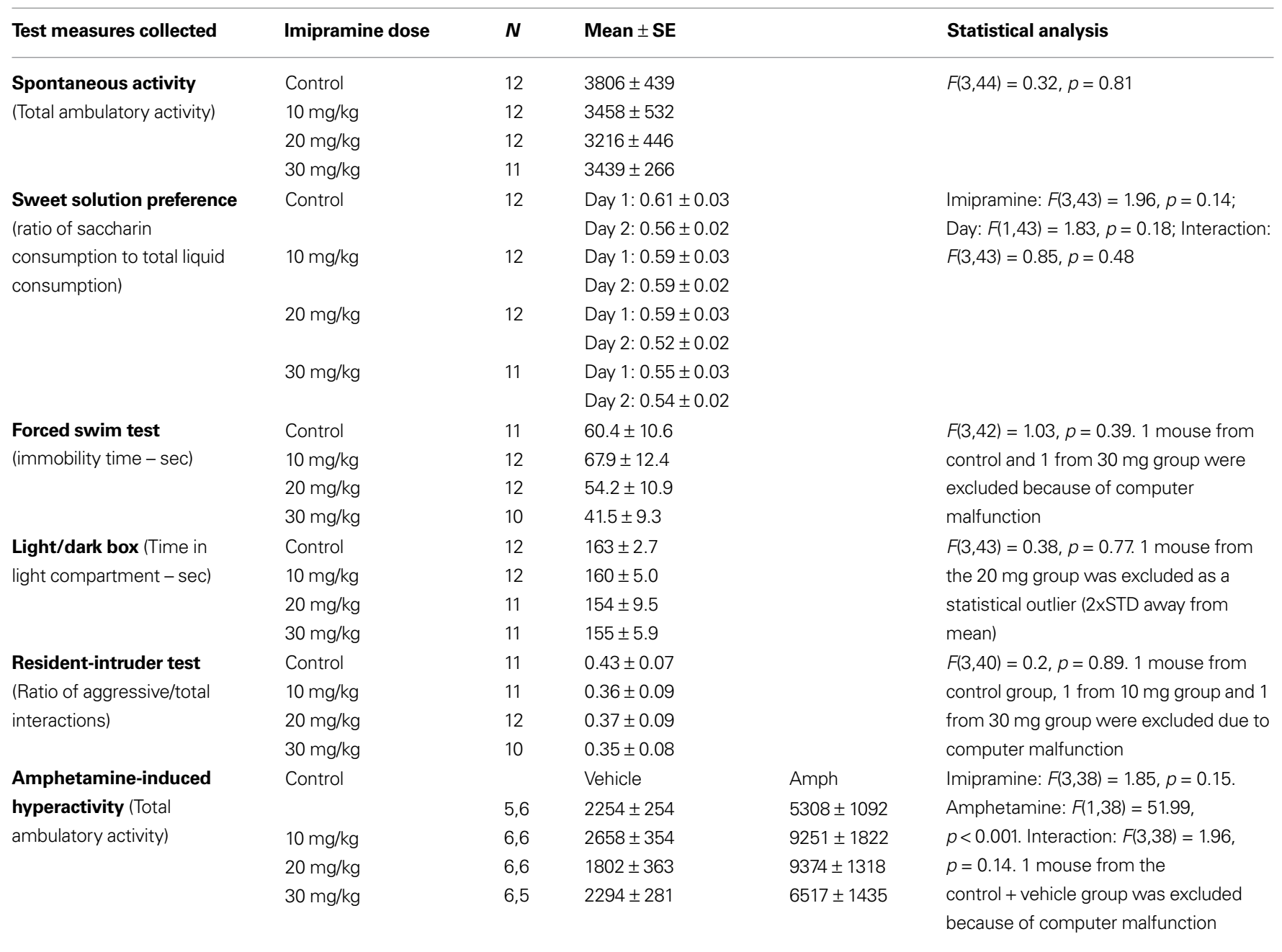

Table 3 |The domains of 'manic-like' behavior modeled in the battery, the expected response and actual response to mood stabilizers in BS mice.

\begin{tabular}{lllll}
\hline Test & $\begin{array}{l}\text { Domain of manic-like } \\
\text { behavior }\end{array}$ & $\begin{array}{l}\text { Expected response to } \\
\text { mood stabilizers }\end{array}$ & $\begin{array}{l}\text { Actual response to } \\
\text { lithium }\end{array}$ & Actual response to valproate \\
\hline $\begin{array}{l}\text { Sweet solution preference } \\
\text { Forced swim test }\end{array}$ & $\begin{array}{l}\text { Reward seeking behavior } \\
\text { Resistance to despair/ } \\
\text { increased vigor }\end{array}$ & $\begin{array}{l}\text { Reduction in preference } \\
\text { Increase in immobility }\end{array}$ & $\begin{array}{l}\text { Reduction in preference } \\
\text { No effect }\end{array}$ & $\begin{array}{l}\text { Reduction in preference } \\
\text { Increase in immobility }\end{array}$ \\
$\begin{array}{l}\text { Resident-intruder test } \\
\text { Dark/light box }\end{array}$ & $\begin{array}{l}\text { Reduced aggression } \\
\text { Risk taking behavior }\end{array}$ & $\begin{array}{l}\text { Reduced time in light } \\
\text { Compartment }\end{array}$ & No effect & No effect \\
Amphetamine-induced & Manic-like increased & Reduced hyperactivity & Reduced hyperactivity & No effect \\
hyperactivity & activity or sensitivity to & & & Reduced hyperactivity (strong \\
psychostimulants & & & trend)
\end{tabular}

to depressenogenic stimuli while in the present study BS mice were found to demonstrate excessive baseline sweet solution preference which was suggested to represent strain-specific, 'manic-like' high reward-seeking behavior (Flaisher-Grinberg et al., 2009). Therefore, the reduction in sweet solution preference induced by valproate and lithium in the current study are in line with the hypothesis and are assumed to represent an anti-manic, rather than an antidepressant effect (see Table 3). A similar idea can be demonstrated regarding drugs effect in the FST. In the present study, valproate was shown to increase immobility time in the FST whereas previous 
studies found that all the drugs used in the present study decrease immobility in the test [lithium (Bersudsky et al., 2007; Gould et al., 2008), valproate (Bourin et al., 1996; Kulkarni and Dhir, 2007), imipramine (Porsolt et al., 1978)]. Importantly, these 'antidepressant-like' effects of both mood stabilizers and antidepressant drugs were demonstrated in studies in which rodent strains with high baseline immobility were used $[\mathrm{C} 57 \mathrm{Bl} / 6$ and NIH-Swiss (Bourin et al., 1996), Swiss mice (Porsolt et al., 1978), CD, NMRI and OF-1 (Porsolt et al., 1978; Swiergiel et al., 2007)]. In the present study, BS mice were found to show low baseline immobility in the FST, a behavior which was suggested to represent 'manic-like' excessive vigor and goal directed activity (Roybal et al., 2007; FlaisherGrinberg and Einat, 2009b). It is therefore reasonable to expect that in these mice the effects of mood stabilizers would be to act as anti-manic, i.e. increase immobility time [valproate (FlaisherGrinberg and Einat, 2009b); current study; lithium, and a number of mutant mice models (Roybal et al., 2007; Engel et al., 2008)]. In contrast, while imipramine is known to reduce immobility time in many strains, it is suggested that its lack of effect in BS mice in the current study reflect a floor effect, due to the low immobility levels demonstrated by BS mice. Although it is possible that different imipramine doses would have produced an effect, this possibility seems less likely given that the doses used in the study were previously demonstrated to have effects in different mice strains.

In the context of the current results, it is important to note that the spontaneous locomotor activity of BS mice was not affected by any of the drugs and therefore it is reasonable to suggest that the effects of the mood stabilizers were not related to a generalized change in activity but are specific to the tests. This is in contrast to strains such as $\mathrm{FVB} / \mathrm{NJ}$ mice or some mice strains with targeted mutations (such as the ERK1 heterozygote mice), which were found to show low immobility in the FST combined with generalized hyperactivity (Engel et al., 2008; Milner and Crabbe, 2008), suggesting a generalized, non specific behavioral change.

In the present study it was hypothesized that valproate and lithium would induce an anti-manic reduction in the risk-taking and aggressiveness demonstrated by BS mice. The lack of drug effect in the light/dark box and the resident-intruder test are in contrast with these hypothesis as well as with previous reports demonstrating anxiolytic effects [imipramine (de Angelis, 1992, 1995); valproate (Yoshimura and Ogawa, 1984; Ibarguen-Vargas et al., 2009)] and anti-aggressive effects [imipramine (Pinna et al., 2004); valproate (Einat, 2007b); lithium (Wei et al., 2007; Uchida et al., 2009; Veenema, 2009; Veenema and Neumann, 2009)] in these tests. The lack of effects in the resident-intruder test could be at least partially explained by the low baseline aggression found in Stage 2 of the present study, which could have created a floor effect masking possible drug effects. It is also possible that the previous exposure of mice to a variety of stressors across the test battery had a significant influence on their behavior, as stress was shown to alter aggressive behavior in mice (e.g., Uchida et al., 2009). In the context of the current study, saccharin deprivation following the establishment of saccharin preference (a possible consequence of the sweet solution preference test, conducted before the resident-intruder test) has been found to influence rodents' aggressive behaviors (Belozertseva et al., 2004). The lack of effect of imipramine in the light/dark box might be explained by the fact that in this test BS mice show no preference for one compartment over the other (baseline behavior is at the range of 150-160 s out of 300-s session, showing lack of preference for either of the compartments and hence, no anxietylike behavior). Since imipramine is expected to reduce anxiety (de Angelis, 1996), the lack of anxiety demonstrated by BS mice in this test might account for its lack of effect.

In the current study, several rodent tests have been proposed as models for some of the domains of mania and the effects of two mood stabilizers and one antidepressant drug in these tests were assessed. However, the spectrum of behaviors demonstrated in the present study is limited compared with the spectrum of mania and additional tests should be devised that might model further domains of the disorder such as reduced sleep, increased sexual drive and abuse of drugs (Einat, 2007a).

The testing of mice in a continuous set of tests demands a number of important considerations. First, although in the current study tests were arranged from less to more intrusive, it is possible that some tests are more susceptible to previous stress than others (see above for the resident-intruder and light/dark box). Another consideration deals with continuous drug administration. Given that tests are conducted sequentially, this factor introduces variability in the time course of drug treatment at the time of the different tests. Although the effects of acute treatment are not always comparable with the effects of sub-chronic or chronic treatments, this factor might be overcome by starting treatments a few days prior to the behavioral testing. Importantly, most mood stabilizers are expected to have more pronounced effects after chronic treatment compared with acute treatment (Kovacsics and Gould, 2009), whereas other drugs may have effects that tolerate across time. Finally, the inclusion of the amphetamine-induced hyperactivity test in the battery imposes the use of a smaller number of mice in each group in this test. Specifically, in the amphetamine-induced hyperactivity test, half the mice assigned to each treatment group in the other tests are treated with amphetamine and half are treated with vehicle. Although in the current study the number of animal per group in the amphetamine-induced hyperactivity tests ranges from 5 to 8 , the findings that lithium and valproate attenuate amphetamineinduced hyperactivity, while imipramine has no effect, are in line with previous reports in rodents [e.g., lithium: (Frey et al., 2006b; Gould et al., 2007; Kim et al., 2008) imipramine: (DziedzickaWasylewska et al., 1997)]. Future experiments will validate these results using a higher number of mice per group.

A different consideration involves timing of testing within the light/dark cycle of the animals. It may seem appropriate to test nocturnal animals during their dark (and not light) phase in a way that will have higher homology with the active phase of diurnal humans. However, the dark phase of nocturnal animals is not the exact reversal of the light phase in diurnal animals as the biology of circadian rhythms is more complicated. For example, although the main circadian hormone melatonin is secreted during the dark in both diurnal and nocturnal mammals, nocturnal mammals are active when melatonin levels are high, while diurnal mammals are active when melatonin levels are low (Challet, 2007). As such, it is possible that regardless of the time of testing, a full homology of the circadian phase between nocturnal mice and diurnal humans is not attainable. Given that the current study did not evaluated the possible effects of light/dark phase on the demonstrated behavioral 
profile, additional studies are now designed to explore the behavioral responses of BS mice in the same battery of tests conducted during the dark phase. Moreover, in an additional project, attempts are currently made to explore the possible utilization of diurnal rodents to model affective disorders (Einat and Kronfeld-Schor, 2009).

To summarize, the current study identified BS mice as a potentially preferred strain for modeling a number of the domains of mania. The unique behavioral phenotype demonstrated by BS mice might also be useful in future attempts to elucidate the molecular, cellular, and genetic factors differentiating BS from the other strains.

\section{REFERENCES}

Agmo, A., Belzung, C., and Giordano, M. (1996). Interactions between dopamine, GABA in the control of ambulatory activity. J. Neural Transm. 103, 925-934.

Agmo, A., Medrano, A., Garrido, N., and Alonso, P. (1997). GABAergic drugs inhibit amphetamine-induced distractibility in the rat. Pharmacol. Biochem. Behav. 58, 119-126.

Anjaneyulu, M., Chopra, K., and Kaur, I. (2003). Antidepressant activity of quercetin, a bioflavonoid, in streptozotocin-induced diabetic mice. J. Med. Food 6, 391-395.

Antelman, S. M., Caggiula, A. R., Kucinski, B. J., Fowler, H., Gershon, S., Edwards, D. J., Austin, M. C., Stiller, R., Kiss, S., and Kocan, D. (1998). The effects of lithium on a potential cycling model of bipolar disorder. Prog. Neuropsychopharmacol. Biol. Psychiatry 22, 495-510.

Arban, R., Maraia, G., Brackenborough, K., Winyard, L., Wilson, A., Gerrard, P., and Large, C. (2005). Evaluation of the effects of lamotrigine, valproate, carbamazepine in a rodent model of mania. Behav. Brain Res. 158, 123-132.

Ashkenazy, T., Einat, H., and KronfeldSchor, N. (2008). We are in the dark here: induction of depression-, anxiety-like behaviours in the diurnal fat sand rat, by short daylight or melatonin injections. Int. J. Neuropsychopharmacol. 17, 1-11.

Belozertseva, I. V., Sukhotina, I.A., Vossen, J. M., and Bespalov, A. Y. (2004). Facilitation of aggressive, sexual behaviors by saccharin deprivation in rats. Physiol. Behav. 80, 531-539.

Bersudsky, Y., Shaldubina, A., and Belmaker, R. H. (2007). Lithium's effect in forced-swim test is blood level dependent but not dependent on weight loss. Behav. Pharmacol. 18, 77-80.

Borison, R. L., Sabelli, H. C., Maple, P. J., Havdala, H. S., and Diamond, B. I. (1978).Lithium prevention of amphetamine-induced 'manic' excitement, of reserpine-induced 'depression' in mice: possible role of 2-phenylethylamine. Psychopharmacology (Berl.) 59, 259-262. M., Baker, G. B., and Colombel, M. C. (1996). A schematic representation of the psychopharmacological profile of antidepressants. Prog. Neuropsychopharmacol. Biol. Psychiatry 20, 1389-1402.

Brimberg, L., Flaisher-Grinberg, S., Schilman, E. A., and Joel, D. (2007). Strain differences in 'compulsive' lever-pressing. Behav. Brain Res. 179, 141-151.

Castro, A. A., Casagrande, T. S., Moretti, M., Constantino, L., Petronilho, F., Guerra, G. C., Calo, G., Guerrini, R., Dal-Pizzol, F., Quevedo, J., and Gavioli, E. C. (2009). Lithium attenuates behavioral, biochemical effects of neuropeptide S in mice. Peptides 30, 1914-1920.

Challet, E. (2007). Minireview: Entrainment of the suprachiasmatic clockwork in diurnal, nocturnal mammals. Endocrinology 148, 5648-5655.

Chang, Y.Y. C., Rapoport, S. I., and Rao, J. S. (2009). Chronic administration of mood stabilizers upregulates BDNF, $\mathrm{Bcl}-2$ expression levels in rat frontal cortex. Neurochem. Res. 34, 536-541.

Cohen, H., Zohar, J., Gidron, Y., Matar, M. A., Belkind, D., Loewenthal, U., Kozlovsky, N., and Kaplan, Z. (2006). Blunted HPA axis response to stress influences susceptibility to posttraumatic stress response in rats. Biol. Psychiatry 59, 1208-1218.

Cousins, D. A., and Young, A. H. (2007). The armamentarium of treatments for bipolar disorder: a review of the literature. Int. J. Neuropsychopharmacol. 10, 411-431.

Crawley, J. N. (1999). Behavioral phenotyping of transgenic, knockout mice: experimental design, evaluation of general health, sensory functions, motor abilities,, specific behavioral tests. Brain Res. 835, 18-26.

de Angelis, L. (1992). The anxiogeniclike effects of pentylenetetrazole in mice treated chronically with carbamazepine or valproate. Methods
Bourin, M., Redrobe, J. P., Hascoet,

Moreover, it is suggested that using an appropriate model animal in a comprehensive set of behavioral tests may assist in distinguishing the effects of existing and novel drugs on specific domains of mania and of bipolar disorder.

\section{ACKNOWLEDGMENTS}

This study was supported by a NARSAD independent investigator award to Haim Einat. The authors would like to thank Hatece Gagne, Ryan Bastle, Jesse Jutten, Chelsey Hannah, Darcie Sackett and Tonya Meinerding for their technical assistance in the conductance of the experiments.

Find. Exp. Clin. Pharmacol. 14, 767-771.

de Angelis, L. (1995). Effects of valproate, lorazepam on experimental anxiety: tolerance, withdrawal,, role of clonidine. Pharmacol. Biochem. Behav. 52, 329-333.

de Angelis, L. (1996). Experimental anxiety, antidepressant drugs: the effects of moclobemide, a selective reversible MAO-A inhibitor, fluoxetine, imipramine in mice. Naunyn Schmiedebergs Arch. Pharmacol. 354, 379-383.

Dziedzicka-Wasylewska, M., Willner, P., and Papp, M. (1997). Changes in dopamine receptor mRNA expression following chronic mild stress, chronic antidepressant treatment. Behav. Pharmacol. 8, 607-618.

Einat, H. (2006). Modelling facets of mania-new directions related to the notion of endophenotypes. J. Psychopharmacol. (Oxford) 20, 714-722.

Einat, H. (2007a). Different behaviors, different strains: potential new ways to model bipolar disorder. Neurosci. Biobehav. Rev. 31, 850-857.

Einat, H. (2007b). Establishment of a battery of simple models for facets of bipolar disorder: a practical approach to achieve increased validity, better screening, possible insights into endophenotypes of disease. Behav. Genet. 37, 244-255.

Einat, H., Chen, G., and Manji, H. (2004) Possible involvement of protein kinase $\mathrm{C}$ (PKC) in bipolar disorder, its treatment. Harefuah 143, 420-425.

Einat, H., Karbovski, H., Korik, J., Tsalah, D., and Belmaker, R.H. (1999). Inositol reduces depressive-like behaviors in two different animal models of depression. Psychopharmacology (Berl.) 144, 158-162.

Einat, H., and Kronfeld-Schor, N. (2009). Diurnal model animals in the study of depression. Front. Neurosci. 3, 242-243.

Einat, H., and Manji, H. K. (2006). Cellular plasticity cascades: genes-to-behavior pathways in animal models of bipolar disorder. Biol. Psychiatry 31, 31.
Einat, H., Yuan, P., Szabo, S. T., Dogra, S., and Manji, H. K. (2007). Protein Kinase C inhibition by tamoxifen antagonizes manic-like behavior in rats: implications for the development of novel therapeutics for bipolar disorder. Neuropsychobiology 55, 123-131.

Engel, S. R., Creson, T. K., Hao, Y., Shen, Y. Maeng, S., Nekrasova, T., Landreth, G. E., Manji, H. K., and Chen, G. (2008). The extracellular signal-regulated kinase pathway contributes to the control of behavioral excitement. $\mathrm{Mol}$. Psychiatry 29, 29.

Flaisher-Grinberg, S., and Einat, $\mathrm{H}$. (2009a). "Mice models for the manic pole of bipolar disorder," in Mood and Anxiety Related Phenotypes in Mice, ed. T. D. Gould (Berlin: Springer Press), 297-326.

Flaisher-Grinberg, S., and Einat, $\mathrm{H}$. (2009b). A possible utilization of the mice forced swim test for modeling manic-like increase in vigor, goal-directed behavior. J. Pharmacol. Toxicol. Methods 59, 141-145.

Flaisher-Grinberg, S., Kronfeld-Schor, N., and Einat, H. (2008). Models of mania: from facets to domains, from animal models to model animals. $J$. Psychopharmacol. (Oxford) 6, 6.

Flaisher-Grinberg, S., Overgaard, S., and Einat, H. (2009). Attenuation of high sweet solution preference by mood stabilizers: a possible mouse model for the increased reward-seeking domain of mania. J. Neurosci. Methods 177, 44-50.

Frey, B. N., Reazza, A. C., Cereser, K. M., Martins, M. R., Valvassori, S. S., Reus, G. Z., Quevedo, J., and Kapczinski, F. (2006a). Effects of mood stabilizers on hippocampus BDNF levels in an animal model of mania. Life Sci. 79, 281-286.

Frey, B. N., Valvassori, S. S., Reus, G. Z., Martins, M. R., Petronilho, F. C., Bardini, K., Dal-Pizzol, F., Kapczinski, F., and Quevedo, J. (2006b). Effects of lithium, valproate on amphetamineinduced oxidative stress generation in an animal model of mania. $J$. Psychiatry Neurosci. 31, 326-332. 
Gessa, G. L., Pani, L., Fadda, P., and Fratta, W. (1995). Sleep deprivation in the rat: an animal model of mania. Eur. Neuropsychopharmacol. 5(Suppl.), 89-93.

Gould, T.D., and Einat, H. (2007). Animal models of bipolar disorder, mood stabilizer efficacy: a critical need for improvement. Neurosci. Biobehav. Rev. 31, 825-831.

Gould, T. D., O’Donnell, K. C., Dow, E. R., Du, J., Chen, G., and Manji, H. K. (2008). Involvement of AMPA receptors in the antidepressant-like effects of lithium in the mouse tail suspension test, forced swim test. Neuropharmacology 54, 577-587.

Gould, T. D., O’Donnell, K. C., Picchini, A. M., and Manji, H. K. (2007). Strain differences in lithium attenuation of $\mathrm{d}$-amphetamine-induced hyperlocomotion: a mouse model for the genetics of clinical response to lithium. Neuropsychopharmacology 32, 1321-1333.

Gould, T. D., Picchini, A. M., Einat, H., and Manji, H. K. (2006). Targeting glycogen synthase kinase-3 in the CNS: implications for the development of new treatments for mood disorders. Curr. Drug Targets 7, 1399-1409.

Hiscock, K. M., Linde, J. A., and Einat, H. (2007). Black Swiss mice as a new animal model for mania: a preliminary study. J. Med. Biol. Sci. 1, 1-6.

Ibarguen-Vargas, Y., Surget, A., Vourc'h, P., Leman, S., Res, C. R., Gardier,A.M., and Belzung, C. (2009). Deficit in BDNF does not increase vulnerability to stress but dampens antidepressant-like effects in the unpredictable chronic mild stress. Behav. Brain Res. 202, 245-251.

Insel, T. R. (2007). From animal models to model animals. Biol. Psychiatry 62, 1337-1339.

Kim, W. Y., Kim, S., and Kim, J. H. (2008). Chronic microinjection of valproic acid into the nucleus accumbens attenuates amphetamine-induced locomotor activity. Neurosci. Lett. 432, 54-57.

Knapp, R. J., Goldenberg, R., Shuck, C., Cecil, A., Watkins, J., Miller, C., Crites, G., and Malatynska, E. (2002). Antidepressant activity of memoryenhancing drugs in the reduction of submissive behavior model. Eur. J. Pharmacol. 440, 27-35.

Kovacsics, C. E., and Gould, T. D. (2009). Shock-induced aggression in mice is modified by lithium. Pharmacol. Biochem. Behav. 94, 380-386.

Kulkarni, S. K., and Dhir, A. (2007). Effect of various classes of antidepressants in behavioral paradigms of despair. Prog. Neuropsychopharmacol. Biol. Psychiatry 31, 1248-1254.

Leucht, S., Hackl, H. J., Steimer, W., Angersbach, D., and Zimmer, R. (2000). Effect of adjunctive paroxetine on serum levels, side-effects of tricyclic antidepressants in depressive inpatients. Psychopharmacology (Berl.) 147, 378-383.

Lien, R., Flaisher-Grinberg, S., Cleary, C., Hejny, M., and Einat, H. (2008). Behavioral effects of $\mathrm{Bcl}-2$ deficiency: implications for affective disorders. Pharmacol. Rep. 60, 490-498.

Machado-Vieira, R., Kapczinski, F., and Soares, J. C. (2004). Perspectives for the development of animal models of bipolar disorder. Prog. Neuropsychopharmacol.Biol.Psychiatry 28, 209-224.

Malatynska, E., and Knapp, R. J. (2005). Dominant-submissive behavior as models of mania, depression. Neurosci. Biobehav. Rev. 29, 715-737.

Malkesman, O., Austin, D. R., Chen, G., and Manji, H. K. (2009). Reverse translational strategies for developing animal models of bipolar disorder. Dis. Model. Mech. 2, 238-245.

Mavrikaki, M., Nomikos, G. G., and Panagis, G. (2009). Effects of mood stabilizers on brain reward processes in rats: studies using the intracranial self-stimulation paradigm. Eur. Neuropsychopharmacol. 19, 205-214.

McQuade,J.A.,Xu, M.,Woods,S.C., Seeley, R. J., and Benoit, S. C. (2003). Ethanol consumption in mice with a targeted disruption of the dopamine-3 receptor gene. Addict. Biol. 8, 295-303.

Miklowitz, D. J., and Johnson, S. L. (2006) The psychopathology, treatment of bipolar disorder. Annu. Rev. Clin. Psychol. 2, 199-235.

Milner, L. C., and Crabbe, J. C. (2008). Three murine anxiety models: results from multiple inbred strain comparisons. Genes Brain Behav. 7, 496-505.

Monleon, S., D’Aquila, P., Parra, A., Simon, V.M., Brain, P.F., and Willner, P. (1995). Attenuation of sucrose consumption in mice by chronic mild stress, its restorationbyimipramine.Psychopharmacology (Berl.) 117, 453-457.

Nakao, K., Higashio, T., and Inukai, T. (1985). Antagonism of picrotoxin against the taming effect of carbamazepine on footshock induced fighting behavior in mice. Jpn. J. Pharmacol. 39, 281-283.

Orsetti, M., Colella, L., Dellarole, A., Canonico, P. L., Ferri, S., and Ghi, P. (2006). Effects of chronic administration of olanzapine, amitriptyline, haloperidol or sodium valproate in naive, anhedonic rats. Int. J. Neuropsychopharmacol. 9, 427-436.

Overstreet, D. H. (1986). Selective breeding for increased cholinergic function: development of a new animal model of depression. Biol. Psychiatry 21, 49-58.

Papp, M., Moryl, E., and Willner, P. (1996). Pharmacological validation of the chronic mild stress model of depression. Eur. J. Pharmacol. 296, 129-136.

Penn, P. E., McBride, W. J., Lumeng, L., Gaff, T. M., and Li, T. K. (1978). Neurochemical, operant behavioral studies of a strain of alcohol-preferring rats. Pharmacol. Biochem. Behav. 8, 475-481.

Pinna, G., Agis-Balboa, R. C., Doueiri, M. S., Guidotti, A., and Costa, E. (2004). Brain neurosteroids in gender-related aggression induced by social isolation. Crit. Rev. Neurobiol. 16, 75-82.

Porsolt, R. D., Bertin, A., and Jalfre, M. (1978). Behavioural despair in rats mice: strain differences, the effects of imipramine. Eur. J. Pharmacol. 51, 291-294.

Ralph-Williams, R. J., Paulus, M. P. Zhuang, X., Hen, R., and Geyer, M. A (2003). Valproate attenuates hyperactive, perseverative behaviors in mutan mice with a dysregulated dopamine system. Biol. Psychiatry 53, 352-359.

Riegel, R. E., Valvassori, S. S., Elias, G., Reus, G. Z., Steckert, A. V., de Souza, B., Petronilho, F., Gavioli, E. C., DalPizzol, F., and Quevedo, J. (2009). Animal model of mania induced by ouabain: evidence of oxidative stress in submitochondrial particles of the rat brain. Neurochem. Int. 55, 491- 495.

Roybal, K., Theobold, D., Graham, A., Dinieri, J.A., Russo, S. J., Krishnan, V. Chakravarty, S., Peevey, J., Oehrlein, N., and Birnbaum, S. (2007). Manialike behavior induced by disruption of CLOCK. Proc. Natl. Acad. Sci. U.S.A. 104, 6406-6411.

Sadock, J., and Kaplan, H. (2002). Synopsis of Psychiatry. Philadelphia: Lippincott \& Williams.

Shaltiel, G., Maeng, S., Malkesman, O. Pearson, B., Schloesser, R. J., Tragon, T., Rogawski,M., Gasior,M.,Luckenbaugh, D., Chen, G., and Manji, H. K. (2008) Evidence for the involvement of the kainate receptor subunit GluR6 (GRIK2) in mediating behavioral displays related to behavioral symptoms of mania. Mol. Psychiatry 13, 858-872.

Smale, L., Heideman, P.D., and French, J.A (2005).Behavioral neuroendocrinology in nontraditional species of mammals: things the 'knockout' mouse CAN'T tell us. Horm. Behav. 48, 474-483.

Suzuki, T., George, F. R., and Meisch, R. A. (1988). Differential establishment maintenance of oral ethanol reinforced behavior in Lewis, Fischer 344 inbred rat strains. J. Pharmacol. Exp. Ther. 245, 164-170.

Swiergiel,A. H., Leskov, I. L., and Dunn, A J. (2007). Effects of chronic, acute stressors, CRF on depression-like behavior in mice. Behav. Brain Res. 20, 20.

Tecott, L. H., and Nestler, E. J. (2004). Neurobehavioral assessment in the information age. Nat. Neurosci. 7, 462-466.

Uchida, N., Egashira, N., Iwasaki, K. Ishibashi, A., Tashiro, R., Nogami, A., Manome, N., Abe, M., Takasaki, K., Mishima, K., Takata, J., Oishi, R., Nishimura, R., and Fujiwara, M. (2009). Yokukansan inhibits social isolation-induced aggression, methamphetamine-induced hyperlocomotion in rodents. Biol. Pharm. Bull. 32, 372-375.

Veenema,A.H. (2009). Early life stress, the development of aggression, neuroendocrine, neurobiological correlates: what can we learn from animal models? Front. Neuroendocrinol. 30, 497-518.

Veenema, A. H., and Neumann, I. D. (2009). Maternal separation enhances offensive play-fighting, basal corticosterone, hypothalamic vasopressin mRNA expression in juvenile male rats. Psychoneuroendocrinology 34, 463-467.

Wei, X.Y., Yang, J.Y., Dong, Y.X., and Wu, C. F. (2007). Anxiolytic-like effects of oleamide in group-housed, socially isolated mice. Prog. Neuropsychopharmacol. Biol. Psychiatry 31, 1189-1195.

Willner, P. (1991). Behavioral models in psychopharmacology. in Behavioral Models in Psychopharmacology: Theoretical, Industrial, Clinical Perspectives, ed. P. Willner (Cambridge: Cambridge University Press), 3-19.

Yoshimura, H., and Ogawa, N. (1984). Pharmaco-ethological analysis of agonistic behavior between resident, intruder mice: effects of psychotropic drugs. Nippon Yakurigaku Zasshi 84, 221-228.

Conflict of Interest Statement: The authors declare that the research was conducted in the absence of any commercial or financial relationships that could be construed as a potential conflict of interest.

Received: 04 February 2010; paper pending published: 22 February 2010; accepted: 29 March 2010; published online: 22 April 2010.

Citation: Flaisher-Grinberg $S$ and Einat $H$ (2010) Strain-specific battery of tests for domains of mania: effects of valproate, lithium and imipramine. Front. Psychiatry 1:10. doi: 10.3389/fpsyt.2010.00010

This article was submitted to Frontiers in Psychopharmacology, a specialty of Frontiers in Psychiatry.

Copyright (c) 2010 Flaisher-Grinberg and Einat. This is an open-access article subject to an exclusive license agreement between the authors and the Frontiers Research Foundation, which permits unrestricted use, distribution, and reproduction in any medium, provided the original authors and source are credited. 